\title{
NAVIGATION OF CATAMARAN USING WIRELESS TECHNOLOGY
}

\author{
Prof. Madhura G Sunil ${ }^{1}$, Prasad Kumar ${ }^{2}$, Priyadarshini B ${ }^{3}$, Rakesh Kumar ${ }^{4}$, Rakshitha B Jain ${ }^{5}$ \\ ${ }^{1}$ Assistant Professor, EWIT, India, g.madhura1@gmail.com \\ ${ }^{2}$ Student, EWIT, India, prasadshetty2216@gmail.com \\ ${ }^{3}$ Student, EWIT, India, priyadarshini.bs1996@gmail.com \\ ${ }^{4}$ Student, EWIT, India, rakeshrock097@ gmail.com \\ ${ }^{5}$ Student, EWIT, India, bjainrakshitha@ gmail.com
}

\begin{abstract}
The aim of the project is to help the fisherman for identify our Indian border in the sea area while fishing. By using the 8 bit microcontroller the specified tasks is used to identify the Lankan border. This project helps us to know our border limit of the navy. By using this system we can avoid unnecessary shooting and unnecessary death. The fisher man can know their limits. The project consists of Transmitting base station, Receiver setup. The base station is placed at the Indo-Lankan border area. The receiver setup is placed at the boat. The transmitting base station transmits the RF signal, the receiver setup is placed inside the boat receives the signal, when the boat is nearing the border line. When the receiver receives the signal, a Message is transmitted to the coastal guard by means of a warning alarm and is given to the fisherman. Due to this instant action, the coastal guard can stop the fisherman in crossing the border.
\end{abstract}

Key words: Zigbee, GPS, GSM, Microcontroller, Wireless network, Fishermen.

\section{INTRODUCTION}

The passionate and consuming issue raised at the exhibit is trespassing of oceanic limit line between Sri Lanka and India. Both Indian and Sri Lankan anglers have been angling into Palk Bay territory for quite a long time. The issue developed simply after a sea assertion was marked by India and Sri Lanka in 1974. Indeed, at first, the 1974 fringe assertion did not influence angling on either side of the outskirt. In 1976, through a trade of letter, the two India, and Sri Lanka consented to quit angling in each other's waters. In any case, the assertion couldn't prevent the anglers from angling in these waters, as anglers know no limit. They, intentionally or accidentally abuse the International Maritime. Boundary Lines looking for a decent catch. It is essential that in spite of the consenting to of oceanic limit arrangements, anglers groups of both the nations proceeded with their angling in the Palk Bay zone gently until the point that the Eelam war softened out up 1983. Regardless, after the finish of War in 2009, the Sri Lankan anglers have been raising their protest to Indian anglers angling in their waters. In this manner, the primary issue with Indian anglers is that countless are subject to angling in Sri Lankan waters, which is precluded by the
1976 Maritime Boundary Agreement. Likewise, a substantial number of Indian anglers are subject to trawling which is restricted in Sri Lanka.

Global Positioning system (GPS) provides a widerange of navigation and timing services. Zigbeetechnology, it can be used for border safety,tracking of boats and ships in the oceans and inthe seas. The current issue of Indian fishermenbeing abducted by the Srilankan fleet is of seriousconcern. This paper serves as a benefit for thesepeople where a GPS system is attached to the boatwhich in turn is connected to buzzer and motordrive. The GPS receives the graphical location ofthe boat in the sea and then triggers a relay and switch off the boat motor. If the border of the country is crossed by the boat, the Topographiclocation of a country"s border can be obtainedwith the information of the latitude and longitudeof the place and location of the boat.The additional advantage from the existing borderalert systems that are already imparted is that, theinterlock of the Zigbee Technology where minuteby minute position of the boat can be received tobase station. But, previous systems employed IRradiations which proved to be quitedisadvantageous and difficult to use. The paperuses a GPS module, Zigbee, microcontrollersand a buzzer system to alert the fishermen. Theexisting system is an inexpensive maritime bordercrossing alert system mainly focused on the smallscale fisherman who lives just near to the povertyline. This system includes data collection unit,processing unit, controlling unit and transmissionunit. The data collection unit consists of locationrecognition components like GPS receiver andother components attached in the boat that contains the boat localization by collecting the geological positions.The processing unit holds the set oflatitude and longitude values of the sea in the formof databases that can be used for comparing thepresent boat position with legal border limits. The controlling unit displays the boat position byusing LCD display and alert to the fishermanthrough the alarm and turn off the boat motor ifthe boat crossed the border. The transmission unitsends the position of the boat in the sea to the basestation through the zigbee transceiver.

\section{EXISTING SYSTEM}

GPS navigators are the best solution to determine one"s position. But, due to their high price,our fishermen cannot afford them. Other option includes using buoys along the 
entire Indianwater boundary. This is a costly process and ocean current and waves can easily disturb theirpositions. Another instance is that coast guards roam around the border and alert thefishermen whenever they tread near the border.

Currently there is no system available for our fishermen in India to get updates on suddenweather changes or natural calamities like hurricane or tsunami alerts or ability to send outdistress messages with their coordinates when in need of assistance or help.We found out that there is a project submitted to KCSCT in 2013 titled "GPS BASEDBORDER ALERT SYSTEM FOR FISHERMEN". The major drawback we found in theproject was the use of GSM technology for the purpose of communication. It is a proven factthat there are no GSM signals available at sea. Thus communication fails.

\section{LITERATURE SURVEY}

D.Jim Isaac et al [1] the paper titled as"Advanced border alert system using GPS and withintelligent Engine control unit "In our system using GPSand GSM, where GPS is used to find the location of theboat. If the boat nearer to the boundary primarily itwarning the fishermen with the alarm and emits thelocation of the boat to the nearest coast office via GSMcommunication. When it further nears the maritimeboundary an interferer is sent to the Engine Control Unitwhich controls the speed of the engine with the help of the electronic fuel injector and its low cost maritime. By thismethod, we can alert the fishermen and also monitor themthereby avoiding banned activities such as smuggling,intruders, etc.

S. Kiruthika et al [2] the paper titled as" AWireless mode of protected defense mechanism to mariners using GSM technology "In our system using onlyGPS to receive the information from the satellite and storedborder locations to detect whether the boat has crossed theborder or not. If so the mariner is alerted and the messageis transmitted to nearby coast office through RF signals atVHF $(30-300 \mathrm{MHz})$ range which covers wide area.

Naveen Kumar.M et al [3] the paper titled as"border alert and smart tracking system with alarm usesDGPS and GSM and this system uses DGPS to track thelocation of the boat and to activate an alarm which consists of a Piezo-buzzer, when the border is move toward orcrossed. Also, in addition, the DGPS information is sent tocontrol office, and also the information is sent to the familyat regular time intervals that are in expectation about theirfamily member's safety.

\section{SYSTEM DESIGN}

The GPS antenna gets the signal from the satellite and the signal is stored in the GPS unit is sent to the PIC microcontroller that stores and retrieve the information to the tracking unit ZigBee. GPS antenna increases the coverage of the signal from the satellite. Using, GPS the signals from the satellite are stronger in day and night regardless of all the climate, the satellite keeps sending signals with no breakage in the communication while decoding the information using the GPS. Wireless transmission of information takes place from the sender side to the monitoring unit ZigBee that stores the raw data for every 60 seconds on the Server. The server database manages the registered users and it stores the values of coordinates and current time in records. The fishermen"s details and the family member"s contacts are saved on the Server. When the anglers cross the maritime border the microcontroller signals the monitoring unit getting the exact location of the vessel, the monitoring unit sends an SMS with the coordinates (longitude and latitude) on google maps, and the fishermen"s live location is sent to the angler"s family or the coastal guards at base station to give assistance for faster recovery. At the same time, the microcontroller signals the boat ignition to set off, stopping the boat to cross the border saving the lives of the fishermen"s.

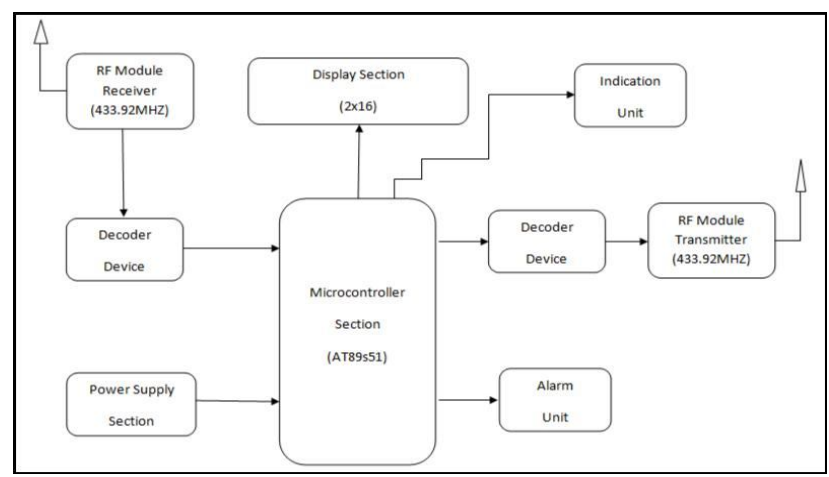

Figure 1: Block diagram of proposed system on the Boat section.

The proposed system is divided into three modules:

1. At the fisherman "s boat

2. One at the navy base station

3. One inside the sea.

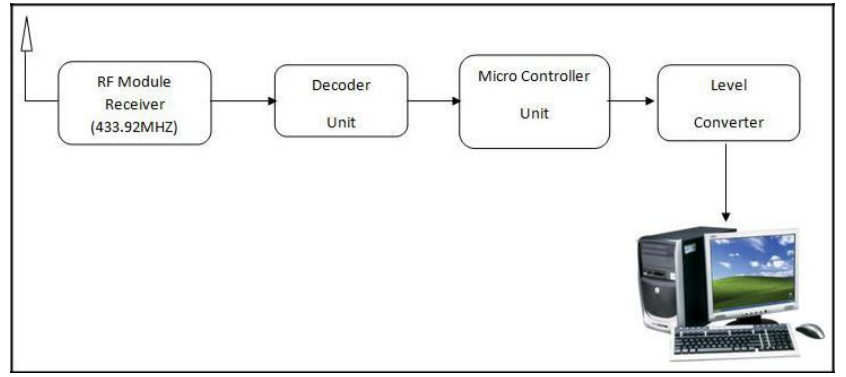

Figure 2:Block diagram of the proposed system at the Navy base station.

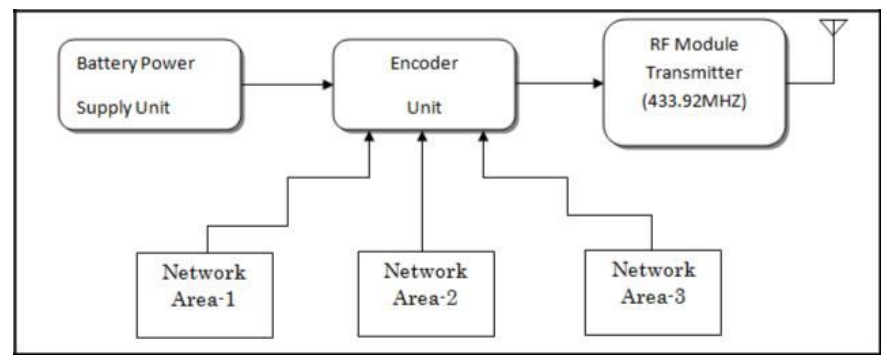

Figure3: Block diagram of the proposed system in the sea 
The system hardware of automatic border crossing detection consists of Power supply unit,GPS, RF Transmitter, RF

Receiver Transmitting and Receiving Antenna, Microcontroller, Relay, Buzzer and DC Motor.

\subsection{Gps (Global Positioning System)}

The Global Positioning System is spacebased satellite navigation system that providesposition and time information in all endureconditions. The two parts of the GPS is transmitterand receiver. The transmitter used to track thelocation with the help of information fromsatellite. The satellite information is taken and thisis sent to the receiver where the exact longitudeand latitude of the place is found. The working ofGPS is explained as follows. First, the signal istransmitted to the satellites and the time taken fortransmission is calculated. Depending on the timetaken, the latitude and longitude information isstored into the receiver.

Each GPS satellite transmits data thatindicates its location and the current time. AllGPS satellites coordinate operations so that theserepeating signals are transmitted at the same time.The signals, moving at the speed of light, enter ata GPS receiver at slightly different times becausesome satellites are left than others. The distance to the GPS satellites can be determined by calculating the amount of time it takes for their signals to reach the receiver. When the receiver calculates the distance to at least four GPS satellites can calculate its position in three dimensions.

\subsection{Microcontroller (Sst89e516rd2)}

The Microcontroller chipused in the project is alow-power, high-performance CMOS 8-bitmicrocomputer with 4 Kbytes of FlashProgrammable and Erasable Read Only Memory(PEROM). The on-chip Flash allows the program memory to be reprogrammed. By combining aversatile 8-bit CPU with Flash, the AtmelAT89C51 is a powerful microcomputer provides ahighly flexible and inexpensive solution to manyembedded control applications. The main use of this microcontroller is totake the data from the GPS device and transfer theinformation to the microcontroller. Theinformation is stored in the microcontrollerEPROM and then depending on the borderinformation the alarm circuit is triggered and thisalerts the people and the relay is tripped for switchoff the boat motor. The information is also sent tothe base station.

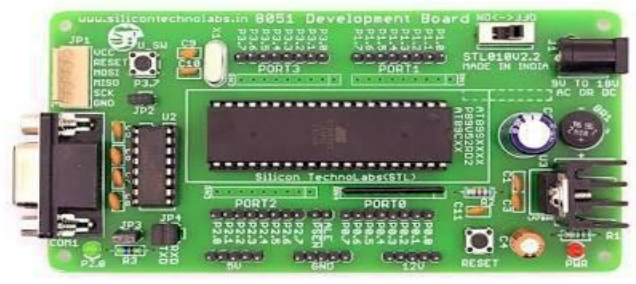

Figure 4: A Microcontroller(SST89E516RD2)

\subsection{Zigbee Transceiver}

Zigbee is a specification for a suite of highlevel communication protocols used to createpersonal area networks. ZigBee is based on anIEEE 802.15 standard. Though low powered,ZigBee devices can transmit data over longdistances by transient data through inter mediatedevices to reach more distant ones, creating amesh network.ZigBee is used in applications that requireonly a low data rate, long battery life, and securenetworking. ZigBee has a defined rate of $250 \mathrm{Kbit} / \mathrm{s}$, best suited for periodic or alternating dataor a single signal transmission from a sensor orinput device. Applications include wireless lightswitches, electrical meters with in homedisplays,traffic management systems, and other

consumerand industrial equipment that require shortrangewireless transfer of data at relatively low rates. The technology defined by the Zigbee specification is intended to be simpler and lessexpensive than other WPANs, such as Bluetoothor Wi-Fi. ZigBee networks are secured by 128 bit symmetric encryption keys Figure.

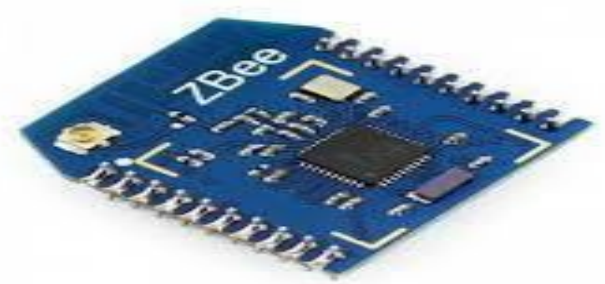

Figure 5:Zigbee Module

ZigBee is used in applications that require only a low data rate, long battery life, and secure networking. Zigbee has a defined rate of $250 \mathrm{Kbit} / \mathrm{s}$, best suited for periodic or intermittent data or a single signal transmission from a sensor or input device. Applications include wireless light switches, electrical meters with in-home-displays, traffic management systems, and other consumer and industrial equipment that requires short-range wireless transfer of data at relatively low rates. The technology defined by the ZigBee specification is intended to be simpler and less expensive than other WPANs, such as Bluetooth or Wi-Fi. ZigBee networks are secured by 128 bit symmetric encryption keys. In home automation applications, transmission distances range from 10 to 100 meters line-of-sight, depending on power output and environmental characteristics.

\subsection{Alarm Circuit:}

Buzzer is used to identify that the vesselhas crossed the border. Under normal conditions,i.e., when boat is within country ${ }^{\text {"es }}$ border, currentflows through emitter. And hence, buzzer is notactivated. When boat crosses border, circuit isclosed and current flows to buzzer. Thus alarm isgenerated. 

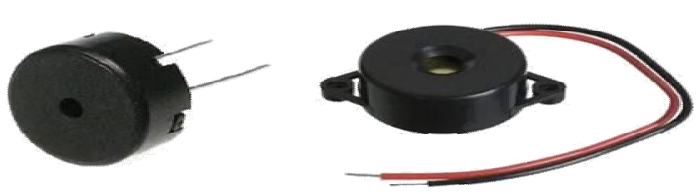

Figure 6:Buzzer Circuit

\subsection{Display Unit}

A LCD display is used for displaying thelatitude and longitude position of the boat. LCDdisplay is connected to port 1 of theMicrocontroller. Every pin of port 1 is connectedto LCD display. Message is sent throughcommands via serial Communication.

\subsection{Relay Switch Circuit}

Relays are electromechanical devices thatuse an electromagnet to operate a pair of movablecontacts from an open position to a closedposition. The advantage of relays is that it takes arelatively small amount of power to operate therelay coil, but the relay itself can be used tocontrol motors, heaters, lamps or AC circuitswhich themselves can draw a lot more electricalpower.

\section{IMPLEMENTATION}

The main aim is to incorporate three main problems faced by our fishermen. They are: Border determination, distress message communication and instant weather updates. We also aim to create a robust system that not only gives both audio and visual alerts when the fisherman crosses the borders border, but we also plan to implement a system where in the fisherman can send an "SOS" signal when he is in trouble at sea, immediately at the push of a button. We are also implementing a system wherein we can transmit sudden weather change information to the fishermen at sea so that they can come back to shore immediately.

\section{Border Determination}

To determine the location of any object on earth, we use GPS coordinates. There are 24 GPSsatellites revolving around the earth at all times. By synchronizing with at least 3 of them wecan obtain the object"s exact latitude and longitude values. We can make use of Radio Frequency (RF) towers to map the borders. We have made use ofFM radio transmitter. Three such towers are used to distinguish three border areas: The Indianborder, The International water border and the other country"s border.Each FM transmitterhas a fixed carrier frequency of $147 \mathrm{MHz}$. Each transmitter is given a different messagefrequency. The message is frequency modulated with the carrier to get the FM signal. Thus, three different FM signals are obtained for three different boundaries.

\section{Distress message communication}

When the fisherman is in distress (example: his boat is sinking) he needs immediate help.Currently there is no system existing to achieve this. We have incorporated an "SOS distresssystem" wherein the fisherman, when in distress has to just push a button. This action willsend out a distress message using wireless zigbee communication to all nearby boats and alsoto the base station. The distress message will contain a predefined message and the latitudeand longitude co-ordinates of the boat when the button was pressed. The coordinates will beobtained using a GPS receiver present on the boat.

\section{Sudden weather change alerting}

Suppose the fisherman has gone out for fishing, and the base station receives (say) a Tsunamialert. This information needs to be immediately sent to the fisherman at sea.Currently there isno such system that meets this demand. We have used RF technology to transmit these "weather update" messages to the fisherman. We have used an audio indicator on the boat toinform him whenever an update is received. Thus he can come back to shore safely.

Present paper is designed using SST89E516RD microcontroller. It is proposed to design an embedded system which is used for automotive security of the coastal border. A microcontroller is used for interfacing to various hardware peripherals. For doing so a SST89E516RD microcontroller is interfaced serially to a GPS Transceiver. An EEPROM is used to store the mobile number. The hardware interfaced to microcontroller are LCD display, GPS Transceiver. The design uses RS-232 protocol for serial communication between the modems and the microcontroller. A serial driver IC is used for converting TTL voltage levels to RS-232 voltage levels. The simulation is carried out by using MPLAB design tool. It is software for microprocessor simulation, schematic capture and printed circuit board (PCB) design. It is developed by Microchip technology. MPLAB is a software package for computer-aided design of electronic circuits. The transmitter section as shown in Figure. 4 produces radio waves with the aid of antenna. The transmitter itself generates a RF alternating current that is applied to the antenna. The transmitter consists of a power supply with which the RF signals are generated.

The package is a system of circuit simulation, based on models of electronic components made in PSpice. A distinctive feature of the package is the possibility of simulating the operation of programmable devices: microcontrollers, microprocessors, DSP and others. Additionally, the package Proteus Professional is a system design of printed circuit boards. MPLAB IDE is an integrated development environment that provides development engineers with the flexibility to develop and debug firmware for various Microchip devices. MPLAB IDE is a Windows-based Integrated Development Environment 
Madhura G Sunil et al., International Journal of Computing, Communications and Networking, 7(2) April - June 2018, 134-138

Incorporated PIC microcontroller (MCU). The receiver Section receives the RF signal from the transmitter and sends to the microprocessor for further processing. .

\section{CONCLUSION}

The proposed paper of zigbee based boat monitoring and border alert system by using zigbee using GPS and ZIGBEE has proven to be a low-cost project. The project also aims at providing peace at the borders and reduces the tensions between the two countries. The proposed system's architecture is reliable and robust. The system will provide high accuracy and high precision values of the Latitude and Longitude. The system proposed will not only alert the fishermen but also carries the information to the base station through the Zigbee transceiver. In case the boat is lost due to rough conditions of the sea (or) intentional crossing of the border is done, then the information is immediately sent to the border security and the necessary action is taken.

In this proposed system fishermen can easily identify the national sea borders and therefore preventing them from entering their area. Thus saving their lives and providing good relationship with the neighboring countries. Also, the piracy of ship can be easily brought under control.

\section{REFERENCES}

1. Bauersfeld, M.L. and Biicking, M. (2011) „A noval approach of Geofencing and Geotagging System based Border Identification", IEEE Aerospace and Electronic Systems Magazine, Vol.12, No.8, pp.2086-2089.

2. Treutter, D. (2014) „, Border Alert System for Boats using ZigBee ee, International Journal of Innovative Research in Computer and Communication engineering, Vol.33, No.19, pp.1295-1395.

3. Zhou Yanming and Xin XueHaoXiaoli , (2014) „, Border alert system for fishermen using GPS ${ }^{\text {ee }}$ International Journal of Students Research in Technology and Management, Vol.02, No.8, pp.3981-3985.

4. Ahmed.M, Ajaz.S, Asim.M, Ozair.M, Siddiqui.M, Mushtaq.Z, "Autonomous Vehicle Monitoring and Tracking System” SCONEST 2005. Pp.1 3, 2005. http://earth.google.com/

5. Tsugawa.S, Tokuda.K, Kato.S, "Digital Cellular Telecommunication System: Lawful interception requirements for GSM," ETSI, ETSITech. Rep. ETR 363, 2009.

6. Alison Brown, Bruce Bockius and Jacob Griesbach, "GPS tracking location-based service using wristwatch geozigbee sensors", IONNTM 2007, San Diego, CA, January 2007.

7. E.DiGiampaolo and F. Martinelli, "Mobile robotlocalization using thephase of passive UHF RFID signals, IEEE Trans. Ind. Electron., vol. 61,no. 1, pp.

365-376, Jan.2014.

https://doi.org/10.1109/TIE.2013.2248333

8. S. Park and H. Lee, "Self-recognition of vehicle position using UHFpassive RFID tags," IEEE Trans. Ind. Electron., vol. 60, no. 1,pp. 226-234, Jan. 2013. https://doi.org/10.1109/TIE.2012.2185018

9. Christo Ananth, I.UmaSankari, A.VidhyaM.Vickneshwari, P.Karthiga, "Efficient Sensor Network for Vehicle Security",International Journal of Advanced Scientific and TechnicalResearch (IJASR), Volume 2, Issue 4, March-April 2014,pp 871-877.

10.C. Zhou and J. D. Griffin, "Accurate phase-based rangingmeasurementsfor backscatter RFID tags," IEEE Antennas Wireless Propag. Lett.,vol.11,pp.152-155,2012.

11. S. S. Saab and Z. S. Nakad, "A standalone RFID indoorpositioningsystem using passive tags," IEEE Trans. Ind.Electron., vol. 58, no. 5,pp. 1961-1970, May 2011. https://doi.org/10.1109/TIE.2010.2055774

12.Jim Isaac, the paper titled as "Advanced border alert system usingGPS and with intelligent Engine control unit "International Journalof Electrical and Computing Engineering (IJECE) Vol. 1, Issue. 4,June 2015

13. S.Kiruthika, N.Rajasekaran the paper titled as" A Wireless mode ofprotected defense mechanism to mariners using GSM technology'International Journal of Emerging Technology and InnovativeEngineering Volume I, Issue 5, May 2015 (ISSN: 2394 - 6598)

14.G.Sivagnanam , A.J.Midhun, N.Krishna, G.Maria Samuel ReubenA.Anguraj5 "Coast guard alert and rescue system for internationalmaritime line crossing of fisherman" " at International Journal ofInnovative Research in Advanced Engineering (IJIRAE) ISSN:2349-2163 Issue 2, Volume 2 (February 2015)

15. NaveenKumar.MRanjith.R The paper titled as" Border alert andsmart tracking system with alarm using DGPS and GSM"International Journal of Emerging Technology in Computer Science\& Electronics (IJETCSE) ISSN: 0976-1353 Volume 8 Issue 1 -APRIL 2014

16.R.Karthikeyan, A .Dhandapani, U.Mahalingham" Protecting ofFishermen on Indian Maritime Boundaries", Journal of ComputerApplications ISSN: 0974 - 1925, Volume-5, Issue EICA2012-3, andFebruary 10, 2012.

17.K. Suresh Kumar, "Design of low cost maritime boundaryidentification device using GPS system" International Journal ofEngineering Science and Technology Vol. 2(9), 2010, 4665-4672.-2010.

18. Abid khan and Ravi Mishra (2012), "GPS - GSM Based TrackingSystem" International Journal of Engineering Trends andTechnology Volume3 Issue2. 